\title{
How to coordinate the relationship between energy consumption's structure transformation and green economic development: From the perspective of technological advancement
}

\section{Fangming Xie}

China University of Mining and Technology

Yali Liu (D m15951758966@163.com )

China University of Mining and Technology https://orcid.org/0000-0001-8886-250X

\section{Fangyuan Guan}

China University of Mining and Technology

\section{Ning Wang}

Jiangsu Normal University kewen college

\section{Research}

Keywords: energy consumption's structure transformation, green economic development, GlobalMalmquist-Luenberger, technological innovation, technological improvement

Posted Date: January 29th, 2020

DOI: https://doi.org/10.21203/rs.2.22212/v1

License: (c) (i) This work is licensed under a Creative Commons Attribution 4.0 International License. Read Full License

Version of Record: A version of this preprint was published at Environmental Sciences Europe on May 6th, 2020. See the published version at https://doi.org/10.1186/s12302-020-00350-5. 


\title{
How to coordinate the relationship between energy consumption's structure transformation and green economic development: From the perspective of technological advancement
}

\author{
Fangming Xie ${ }^{1}$, Yali Liu ${ }^{1,}$, Fangyuan Guan ${ }^{1}$, Ning Wang ${ }^{2}$ \\ 1 School of Management, China University of Mining \& Technology, Xuzhou 221116, China; \\ m15246349728@163.com (F.X.),vaol6617@126.com (F.G.) \\ 2 Jiangsu normal university kewen college, Xuzhou 221116, China; 1871714859@qq.com (N.W.) \\ * Correspondence: m15951758966@163.com; Tel.: +86-0516-8359-0168
}

\begin{abstract}
Background: Green economic development refers to reducing pollution emissions and increasing production efficiency while promoting economic growth. Although the transformation of energy consumption's structure is "green," it may not promote green economic development due to the constraints of existing technical conditions. Thus, the development and use of renewable energy may be detrimental to production efficiency and economic growth. Therefore, the technological advancement approach that can help coordinate the relationship between energy consumption structural transformation and green growth should be identified. In addition, we should determine whether to develop new technologies or improve existing ones.
\end{abstract}

Results: This paper uses the Global-Malmquist-Luenberger approach based on Slacks-Based Measure method to measure the levels of green economic development among the 27 member states of the European Union (excluding the Republic of Malta). Moreover, this study focuses on the impact of energy consumption's structure transformation on green economic development through the threshold regression method. Empirical results reveal (1) the inverted N-shaped relationship between energy consumption's structure transformation and green economic development under the existing technical conditions. The degree of energy consumption's structure transformation can merely promote green economic development in the interval of $0.67-10.87$. That is, the renewable energy consumption ( $\%$ of total energy consumption) is less than $0.67 \%$ or greater than $10.87 \%$, which is not conducive to green economic development. (2) Developing new technologies can stimulate the positive effect of energy consumption's structure transformation on green economic development. However, the improvement of existing technologies fail to exhibit an effective impact on the relationship between energy consumption's structure transformation and green economic development. (3) Coordinating the relationship between energy consumption's structure transformation and green economic development can also be achieved by reducing the dependence of Gross Domestic Product (GDP) on fossil fuels.

Conclusions: With the existing technical conditions, the blind development and use of renewable energy may not be conducive to green economic development. When the degree of energy consumption's structure transformation exceeds an appropriate range, it will adversely affect green economic development. Therefore, in order to better coordinate the relationship between energy consumption's structure transformation and green economic development, European Union member states, especially those with a high degree of energy consumption's structure transformation, should paid more attention to develop new energy technologies rather than improve existing ones. In addition, to mediate the transformation of energy consumption's structure that promotes green economic development, we must prioritize and adjust the industrial 
structure and rationally allocate resources to reduce the GDP's on fossil energy prior to increasing the intensity of renewable energy consumption.

Keywords: energy consumption's structure transformation; green economic development; Global-Malmquist-Luenberger; technological innovation; technological improvement

\section{Background}

Although energy consumption is still dominated by fossil energy consumption in recent years, the rapid growth of renewable energy consumption indicates that the energy consumption's structure gradually transforms into renewable energy consumption. Countries worldwide are actively developing and using renewable energy to achieve the United Nations Sustainable Development Goals [1] and to prepare for sustainable development. The European Union (EU) holds the world's leading renewable energy technologies and a high demand for renewable energy. Therefore, the transformation of the energy consumption's structure in EU has recently achieved certain results. Figure 1 illustrates that the proportion of renewable energy consumption has grown rapidly in EU from 2008 to 2018.

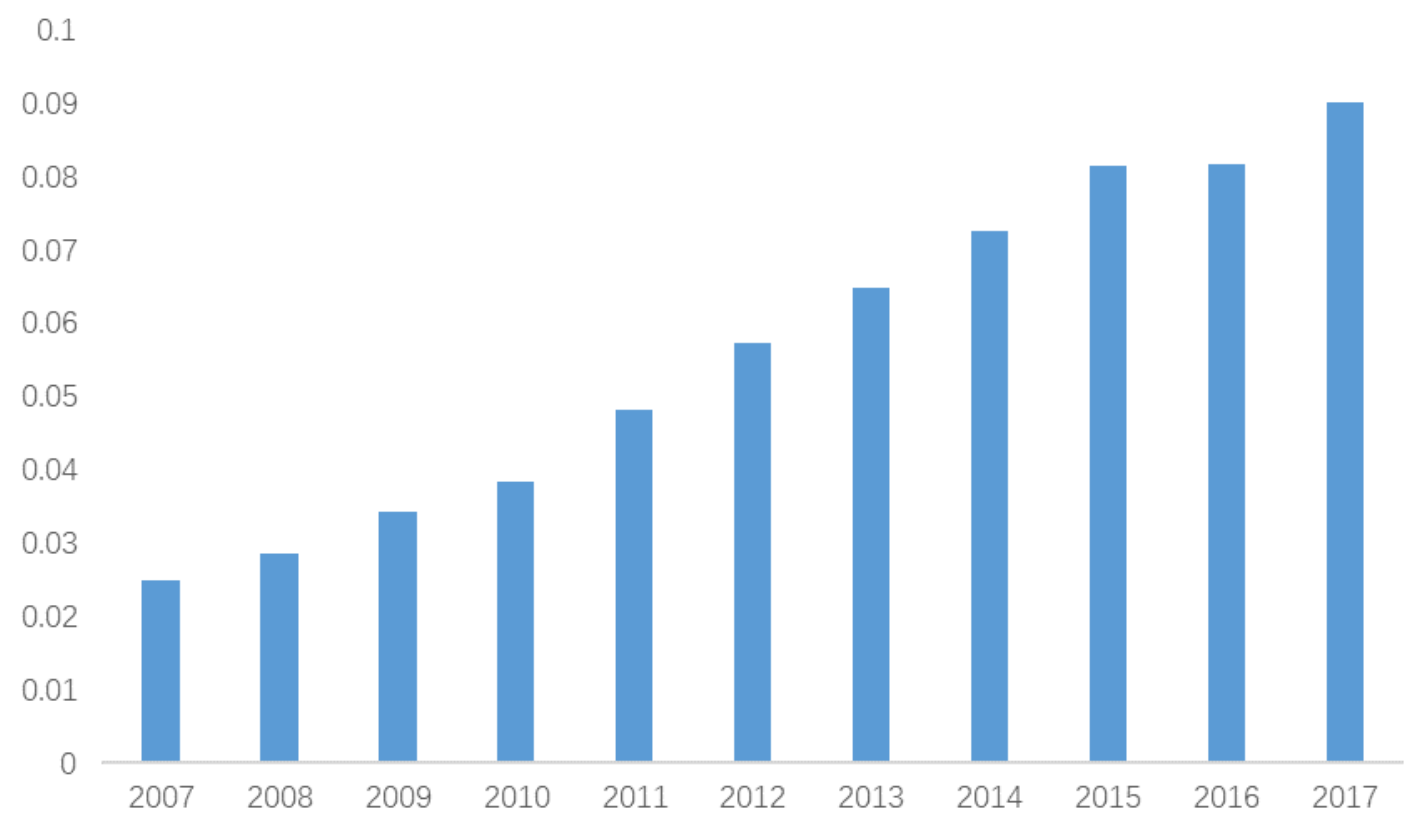

Figure 1. Renewable energy consumption (\% of total energy consumption) in EU.

Data Sources: BP Statistical Review of World Energy, 2019 [2]

To achieve sustainable development, the European Parliament proposed in 2017 that the EU's renewable energy consumption should account for $35 \%$ of total energy consumption by 2030 [3]. The pace of energy consumption's structure transformation is predicted to accelerate, and the intensity of renewable energy consumption will exceed and consequently replace fossil energy. The BP Statistical Review of World Energy classifies renewable energy sources as solar, wind, biomass, wave, tidal, and geothermal, among others. As an environmentally friendly resource, renewable energy is certainly "green," but it fails to necessarily promote "development." For instance, fossil energy uses considerably more time and a wider range than renewable energy and is more suitable for current production technology. That is, the role of energy consumption's structural transformation in green economic development is subject to existing technical conditions. Therefore, an investigation of whether technological advances help coordinate the relationship between energy consumption structural transformation and green economic development must be undertaken. In addition, we should determine whether new technologies must be developed or existing ones must be improved. In the context of the rapidly growing renewable energy consumption, countries 
struggle to stimulate the transformation of energy consumption's structure to acquire a positive effect on green economic development.

The Organization for Economic Co-operation and Development (OECD) defines green economic development as the promotion of economic growth while ensuring that the nature can continuously provide resources and environmental services for humans' wellbeing [4]. That is, green economic development refers to reducing pollution and improving the efficiency of resource utilization while promoting economic growth. Green economic development focuses on three aspects, namely, pollution reduction, efficient resource utilization, and economic growth. Therefore, green economic development further satisfies the requirements of sustainable development. By investigating the relationship between energy consumption's structure transformation and green economic development, this study can provide scientific policy recommendations for immediately achieving sustainable development.

This paper is unique given that it employs the global Malmquist-Luenberger index based on slacks-based measure (SBM-GML) approach to measure the green economic development among the 27 EU Member States. This paper aims to analyze whether technological innovation and technological improvement can coordinate the relationship between energy consumption's structure transformation and green economic development. Moreover, this study integrates the empirical results to outline scientific policy recommendations.

The remainder of this study is organized as follows. Section 2 reviews related studies; section 3 describes the data and the methodology; section 4 combines the empirical results to propose four conclusions, and section 5 summarizes the main findings and proposes scientific policy recommendations.

\section{Literature Review}

Relevant studies mainly discuss the relationship between renewable energy consumption and economic growth, but consistent conclusions have not been reached.

First, certain studies have indicated that the transformation of energy consumption's structure will acquire a positive impact on economic growth. This finding was supported by the fact that renewable energy consumption can completely replace fossil energy consumption and promote economic growth along with fossil energy.

Tugcu et al. (2012) indicated that renewable and fossil energy consumption can likewise acquire a positive impact on economic growth in G7 countries [5]. Lin and Moubarak (2014) proved that China's economic growth benefits from the renewable energy industry. That is, energy consumption's structure transformation can support China's economic growth [6]. Apergis and Payne (2010) [7], Sebri and Ben-Salha (2014) [8], Marinas et al. (2018) [9] proved the long-term bidirectional Granger causality between renewable energy consumption and economic growth and found that the transformation of energy consumption's structure can enhance economic growth. Shafiei and Salim (2014) [10], Bhattachary et al. (2015) [11], Paramati et al. (2018) [12], Rahman and Velayutham (2019) [13] asserted that the renewable energy consumption acquires a positive effect on economic activities. Lnglesi-Lotz (2016) pointed out that increasing the intensity of renewable energy consumption solves environmental pollution and improves the level of economic growth [14]. Alper and Oguz (2016) used the Auto Regressive Distributed Lag (ARDL) approach to prove that energy consumption's structure transformation acquires positive effects on economic growth for all EU member states [15]. Eren et al. (2019) used the Dynamic Ordinary Least Squares approach and proved that renewable energy consumption improves India's economic growth and financial development [16].

Second, certain studies have emphasized that the transformation of energy consumption's structure negatively affects economic growth. This finding is explained by the notion that the development and use of renewable energy generate substantial economic costs, thereby causing economic burden.

Ocal and Aslan (2013) used the ARDL model and proved that the transformation of energy consumption's structure is not conducive to economic growth in Turkey [17]. Similarly, Destek (2016) 
found that renewable energy consumption is not conducive to India's economic growth [18]. Wang et al. (2018) used the Two-Stage Least Square approach to prove that the transformation of energy consumption's structure discourages economic growth in Pakistan [19]. Khoshnevis and Bahram (2017) [20], Sasana and Ghozali (2017) [21], Magazzino (2017) [22] asserted that renewable energy consumption will have an adverse impact on economic activities. Ozcan and Ozturk (2019) pointed out that renewable energy consumption may have detrimental effects on economic performance level [23].

Finally, the expanding research has indicated that the impact of renewable energy consumption on economic growth may change in different situations. Thus, a nonlinear relationship exists between the transformation of energy consumption's structure and economic growth.

Destek and Aslan (2017) investigated the impact of renewable energy consumption on the economic growth of 17 countries. They emphasized that renewable energy consumption can merely promote economic growth in Peru, Greece, and South Korea [24]. Narayan and Doytch (2017) proved that renewable energy consumption in low- and middle-income countries can promote economic growth. However, renewable energy consumption in countries with high-income level exhibits no impact on economic growth [25]. Xie et al. (2018) used the data from seven countries with high energy consumption levels and demonstrated a nonlinear relationship between renewable energy consumption and economic growth. Furthermore, they pointed out that technological upgrading can stimulate the energy consumption's structure to positively affect economic growth [26]. Destek and Sinha (2019) found the U-shaped relationship between renewable energy consumption and economic growth among 24 OECD countries [27].

Although scholars have focused on the relationship between renewable energy consumption and economic growth in the relative studies, they failed to analyze the relationship between the energy consumption's structure transformation and green economic development. As one of the keys to achieving sustainable development, green economic development should be valued.

Several studies have proved that technological advancement can stimulate the positive effects of renewable energy consumption on economic development. If technological advancement can stimulate the energy consumption's structure transformation, will it exhibit a positive effect on green economic development? Which technological advancement approaches can coordinate the relationship between energy consumption's structure transformation and green economic development? Should we develop a new and high-tech solution or improve existing ones? This present study responds to the requirements of sustainable development and analyzes the possibility of coordinating the relationship between energy consumption's structure transformation and green economic development through technological advancement.

\section{Methodology}

\subsection{Data and measurements}

\subsubsection{Subsubsection}

Following the OECD definition of green economic development, we believe that green economic development requires the reduction of pollution emissions and the increase in production efficiency while promoting economic growth. Therefore, this present study uses the SBM-GM approach with desired and undesired outputs to measure the increase in green total factor productivity among the 27 member states of the EU and expresses the level of green economic development.

Combining with the study of Luenberger (1995) [28], Chung et al. [29] applied the direction distance function to the Malmquist approach. He used the Malmquist-Luenberger index based on Slacks-Based Measure (SBM-ML) approach to measure the total factor productivity with undesired outputs. Using the ML approach, Yoruk and Zaim (2005) [30], Kumar (2006) [31], Feng and Apostolos (2014) [32] used GDP as the desired output and pollutant emissions as the undesired output. Oh [33] built the global Malmquist-Luenberger (GML) approach based on SBM-ML 
approach. Compared with the SBM-ML approach, the SBM-GML approach can address the unsolvable problem of linear programming.

This paper uses the SBM-GML approach to measure the green economic development (Green) levels among the $27 \mathrm{EU}$ member countries. The desired output is GDP, whereas the undesired output is carbon dioxide emission. Moreover, the input factors include capital stock, total labor force, and total energy consumption. Table 1 presents the green economic development index evaluation system.

Table 1. Green economic development Index Evaluation System.

\begin{tabular}{|c|c|c|c|}
\hline Category & Variable & Description & Unit \\
\hline \multirow{3}{*}{ Input Factor } & Capital stock & $\begin{array}{c}\text { Total capital } \\
\text { formation of the } \\
\text { countries }\end{array}$ & Current US dollar \\
\hline & Total labor force & $\begin{array}{c}\text { Total labor force of } \\
\text { the countries }\end{array}$ & People \\
\hline & $\begin{array}{l}\text { Total energy } \\
\text { consumption }\end{array}$ & $\begin{array}{c}\text { Total energy } \\
\text { consumption of the } \\
\text { countries }\end{array}$ & $\begin{array}{l}\text { Million tons oil } \\
\text { equivalent }\end{array}$ \\
\hline Desired Output & GDP & $\begin{array}{l}\text { Gross Domestic } \\
\text { Product of the } \\
\text { countries }\end{array}$ & Current US dollar \\
\hline Undesired Output & $\begin{array}{l}\text { Carbon dioxide } \\
\text { emission }\end{array}$ & $\begin{array}{l}\text { Carbon dioxide } \\
\text { emissions of the } \\
\text { countries }\end{array}$ & $\begin{array}{l}\text { Million tons of } \\
\text { carbon dioxide }\end{array}$ \\
\hline
\end{tabular}

Through the SBM-GML approach, we can obtain the green economic development level of each country, as well as the technological progress rate and technical efficiency by decomposing the GML index. Explanatory variable: Energy consumption's structure transformation (EST) indicates renewable energy consumption (\% of total energy consumption).

Threshold variable: Technological innovation (TC) indicates the technological progress rate. Technical efficiency (EC) denotes technical efficiency. Fossil energy dependence (FED) refers to the contribution of fossil energy consumption to GDP, which is indicated by fossil energy consumption (\% of GDP). We also use EST as the threshold variable to analyze the optimal range of energy consumption's structure transformation that promotes green economic development under the existing technology conditions.

Controlled Variable: The population density (DEN) is indicated by the logarithm of the number of people per kilometer of land area. Government intervention (GOV) substitutes the total government financial expenditure (\% of GDP). Unemployment rate (UNE) substitutes the total number of unemployed (\% of total labor).

The empirical analysis employs the annual panel data of the $27 \mathrm{EU}$ member countries (excluding the Republic of Malta) from 2008 to 2017. All data are gathered from the 2019 BP Statistical Review of World Energy and World Bank WDI Database. Table 2 reports the summary statistics of the variables.

Table 2. Statistical description of variables.

\begin{tabular}{cccccc}
\hline Variables (Units) & Observation & $\begin{array}{c}\text { Average } \\
\text { Value }\end{array}$ & $\begin{array}{c}\text { Standard } \\
\text { Deviation }\end{array}$ & $\begin{array}{c}\text { Minimum } \\
\text { Value }\end{array}$ & $\begin{array}{c}\text { Maximum } \\
\text { Value }\end{array}$ \\
\hline Green(-) & 270 & 1.022 & 0.138 & 0.661 & 1.674 \\
EST (\%) & 270 & 3.387 & 3.711 & 0.003 & 20.439 \\
TC (-) & 270 & 1.025 & 0.187 & 0.439 & 1.819 \\
\hline
\end{tabular}




\begin{tabular}{cccccc}
\hline $\begin{array}{c}E C(-) \\
\begin{array}{c}F E D /(\text { Million } \\
\text { toe/Billions of US }\end{array}\end{array}$ & 270 & 1.012 & 0.124 & 0.617 & 1.661 \\
$\begin{array}{c}\text { dollars) } \\
\text { DEN/(people) }\end{array}$ & 270 & 0.106 & 0.056 & 0.034 & 0.312 \\
GOV/ (\%) & 270 & 4.612 & 0.774 & 2.861 & 6.231 \\
UNE (\%) & 270 & 38.991 & 7.068 & 17.616 & 62.381 \\
\hline
\end{tabular}

\subsection{Modeling}

This study constructs the threshold models based on the threshold regression proposed by Hansen [34]. The threshold model aids in investigating whether technology innovation and technology improvement can affect the relationship between energy consumption's structure transformation and green economic development.

The construction process of the threshold models is as follows:

$$
\text { Green }_{i t}=\mu_{i}+\beta^{\prime} E S T_{i t} I\left(q_{i t} \leq \gamma\right)+\beta_{2}^{\prime} E S T_{i t} I\left(q_{i t}>\gamma\right)+\lambda x_{i t}+\varepsilon_{i t}
$$

where Greenit and ESTit are the values of Green and EST, respectively, in country $i$ at $t$ period. $q_{i t}$ represents the threshold variables. $\beta_{1}^{\prime}, \beta_{2}^{\prime}$ are coefficients to be estimated for EST. $X_{i t}$ represents the controlled variables. $\lambda$ denotes the coefficient to be estimated for the

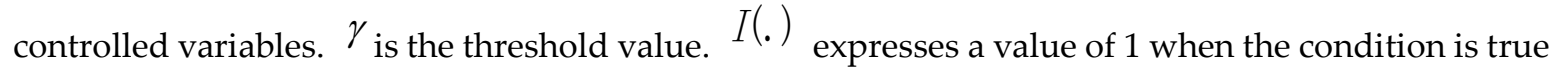
and 0 when the condition is not true. ${ }^{\varepsilon_{i t}}$ is the random error term. ${ }^{\mu_{i}}$ is an unknown parameter vector.

The threshold regression is divided into two regime, while the sum of the squared errors calculations is as follows:

$$
S_{1}(\gamma)=\hat{e}^{*}(\gamma)^{\prime} \hat{e}^{*}(\gamma)=\operatorname{Green}_{i t}{ }^{*}\left(1-\operatorname{EST}_{i t}{ }^{*}(\gamma)^{\prime}\left(x^{*}(\gamma)^{\prime} \operatorname{EST}_{i t}{ }^{*}(\gamma)\right)^{-1} X^{*}(\gamma)^{\prime}\right) \text { Green }_{i t}{ }^{*}
$$

where $\operatorname{EST}_{i t}(\gamma)=\left(\begin{array}{c}E S T_{i t} I(q \leq \gamma) \\ E S T_{i t} I(q>\gamma)\end{array}\right) ; \operatorname{Green}_{i t}{ }^{*}=$ Green $_{i t}-$ Green $_{i t} ; \quad e_{i t}{ }^{*}=e_{i t}-\bar{e}_{i t}$; $E S T_{i t}^{*}=E S T_{i t}-\operatorname{EST}_{i t} \quad ; \quad \hat{\beta}(\gamma)=\left(\operatorname{EST}^{*}(\gamma)^{\prime} \operatorname{EST}^{*}(\gamma)\right)^{-1} \operatorname{EST}^{*}(\gamma)^{\prime} \operatorname{Green}^{*} \quad$; $\hat{e}^{*}(\gamma)=$ Green $^{*}-\operatorname{EST}^{*}(\gamma) \hat{\beta}^{*}(\gamma)$. Moreover, $\gamma$ can be estimated by least squares and can be easily determined by minimization of the concentrated sum of the squared errors (2). The least squares estimators are as follows:

$$
\hat{\gamma}=\underset{\gamma}{\arg \min } S_{1}(\gamma) .
$$

After $\hat{\gamma}$ is obtained, the residual variance is as follows:

$$
\hat{\sigma}^{2}=\frac{1}{n(T-1)} \hat{e}^{*^{\prime}} \hat{e}^{*}=\frac{1}{n(T-1)} S_{1}(\hat{\gamma}) .
$$

Only one $\gamma$ value exists in formula (1); thus, formula (1) is a single threshold model. If multiple threshold values are present for the threshold variable, then we can construct a panel threshold model with multiple threshold values. Thus, formula (2) is expressed as:

$$
\begin{aligned}
& \text { Green }_{i t}=\mu_{i}+\beta^{\prime} E S T_{i t} I\left(q_{i t} \leq \gamma_{1}\right)+\beta_{2}^{\prime} E S T_{i t} I\left(\gamma_{1}<q_{i t} \leqslant \gamma_{2}\right)+\cdots \\
& +\beta_{n}^{\prime} E S T_{i t} I\left(\gamma_{n-1}<q_{i t} \leqslant \gamma_{n}\right)+\lambda x_{i t}+\varepsilon_{i t}
\end{aligned}
$$


The threshold models above can be implemented in Stata14.

\section{Results and discussion}

The Hausman test is initially employed to detect the endogeneity between Green and EST. Table 3 reports the test results. Evidently, given that the error coefficient is insignificant, we cannot reject the null hypothesis of endogeneity. Therefore, the threshold model can provide robust results without endogeneity.

Table 3. Threshold value estimates

\begin{tabular}{|c|c|c|c|}
\hline & Coefficient & p-value & H0: No endogeneity is evident. \\
\hline EST & 2.87 & 0.579 & The null hypothesis of endogeneity was not rejected. \\
\hline
\end{tabular}

The Bootstrap approach is used to calculate the threshold value in this study. All the data are repeatedly sampled for 300 times through the repeated Bootstrap approach to obtain robust values. Tables $4 \mathrm{a}$ and $4 \mathrm{~b}$ indicates the calculation result of the threshold value.

We performed a significant test on the threshold values, and the test results are shown in Table 4a. Evidently, when EST and TC are used as the threshold variables, two threshold values pass the significance test. In addition, when EC and FED are used as the threshold variables, only a threshold value passes the significance test.

Table 4a. Test for threshold value.

\begin{tabular}{|c|c|c|c|c|c|c|c|c|c|c|c|c|}
\hline \multirow[b]{2}{*}{ Variables } & \multicolumn{6}{|c|}{ Test for Single Threshold Value } & \multicolumn{6}{|c|}{ Test for Double Threshold Value } \\
\hline & $\begin{array}{c}\text { F } \\
\text { Value }\end{array}$ & $\begin{array}{c}p \\
\text { Value }\end{array}$ & BS & $10 \%$ & $5 \%$ & $1 \%$ & $\begin{array}{c}\text { F } \\
\text { Value }\end{array}$ & $\begin{array}{c}p \\
\text { Value }\end{array}$ & BS & $10 \%$ & $5 \%$ & $1 \%$ \\
\hline EST & 16.87 & 0.00 & 300 & 8.01 & 9.81 & 12.64 & 4.34 & 0.08 & 300 & 12.81 & 16.54 & 21.11 \\
\hline$T C$ & 55.49 & 0.00 & 300 & 10.53 & 13.79 & 18.47 & 48.15 & 0.00 & 300 & 10.13 & 13.11 & 17.08 \\
\hline$E C$ & 12.10 & 0.03 & 300 & 7.21 & 9.15 & 14.56 & 1.38 & 0.91 & 300 & 9.72 & 12.17 & 18.75 \\
\hline FED & 16.90 & 0.01 & 300 & 10.15 & 12.09 & 16.16 & 8.12 & 0.13 & 300 & 9.81 & 12.18 & 15.14 \\
\hline
\end{tabular}

We calculate the corresponding threshold values after the number of thresholds are determined. Table $4 \mathrm{~b}$ presents that the threshold values of the EST are 0.67 and 10.87; the threshold values of the TC are 0.75 and 1.23 , the threshold value of the EC is 1.03 , and the threshold value of the FED is 0.13 .

Table $4 \mathrm{~b}$. Calculation result of threshold values.

\begin{tabular}{ccc}
\hline Variables & Threshold Value 1 [Lower Upper] & Threshold Value 2 [Lower Upper] \\
\hline EST & $0.67[0.290 .83]$ & $10.87[10.8410 .88]$ \\
TC & $0.75[0.730 .77]$ & $1.23[1.201 .24]$ \\
EC & $1.03[1.011 .05]$ & \\
FED & $0.13[0.120 .14]$ & \\
\hline
\end{tabular}

The impact of energy consumption's structure transformation on green economic development is subsequently analyzed through the threshold regression models. Table 5 reports the results. Models 1, 2, 3, and 4 indicate that EST, TC, EC, and FED are used as threshold variables.

Table 5. Threshold model regression results.

\begin{tabular}{cccccc}
\hline \multirow{2}{*}{ Green } & Fixed Effect & \multicolumn{4}{c}{ Panel Threshold Model } \\
\cline { 3 - 6 } & Model & Model 1 & Model 2 & Model 3 & Model 4 \\
\hline \multirow{2}{*}{ EST } & $0.006^{* * *}$ & $-1.649^{* *}(0.014)$ & $-0.109^{* * *}(0.000)$ & $-0.053(0.33)$ & $0.054^{* *}(0.011)$ \\
\cline { 3 - 6 }
\end{tabular}




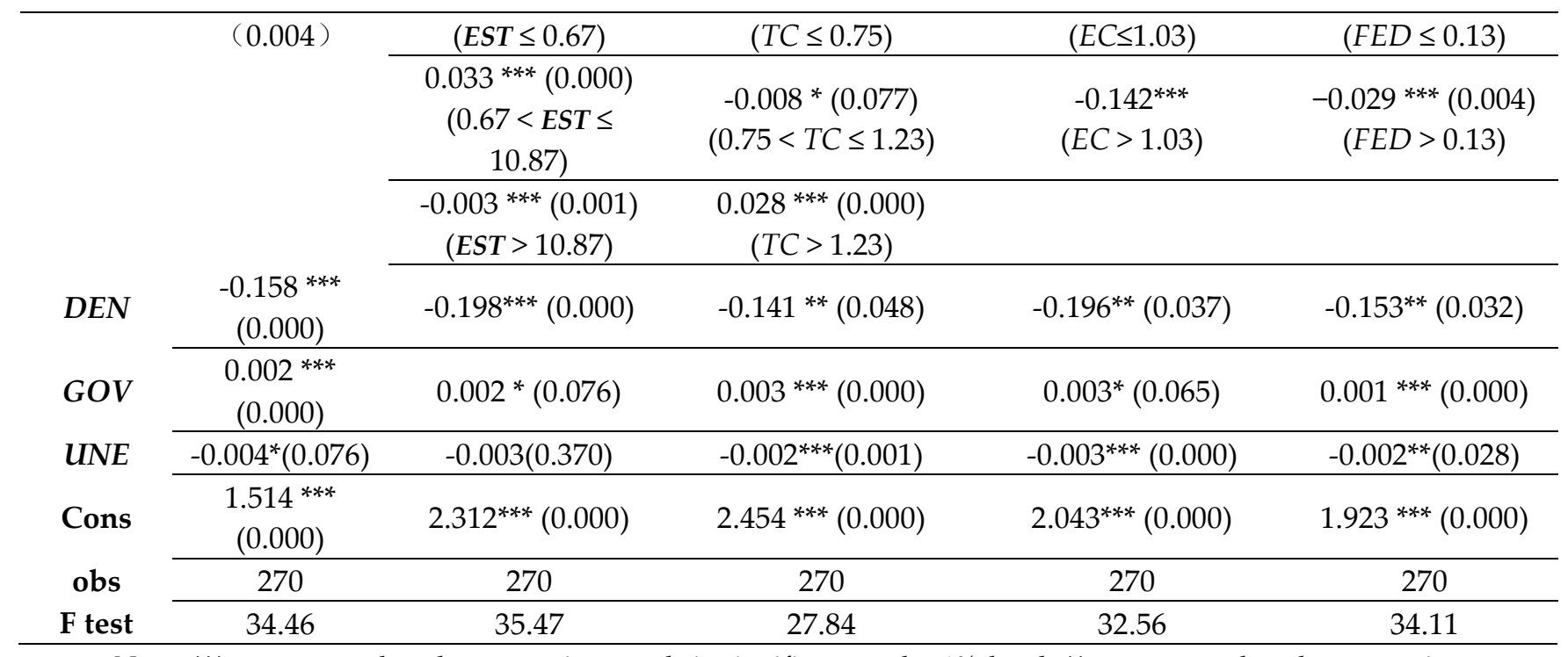

Note: ${ }^{* *}$ represents that the regression result is significant at the $1 \%$ level; ${ }^{* *}$ represents that the regression result is significant at the $5 \%$ level; and * represents that the regression result is significant at the $10 \%$ level.

The following conclusions are derived from the empirical results of Models 1, 2, 3, and 4 .

(1) Model 1 reveals the inverted N-shaped relationship between energy consumption's structure transformation and green economic development under the existing technical conditions. In particular, when the EST level is lower than 0.67, the energy consumption's structure transformation exhibits a significant negative impact on green economic development, while the marginal coefficient is -1.649 . The EST level that is higher than 0.67 but lower than 10.87 indicates that the transformation of energy consumption's structure have a significant positive impact on green economic development, and the marginal coefficient is 0.033 . By contrast, when the EST level is higher than 10.87, the energy consumption's structure transformation exhibits a significant negative impact on green economic development, while the marginal coefficient is -0.003 .

This study combines the scale effect [35] to explain the results of Model 1. When the degree of energy consumption's structure transformation is less than 0.67 , the scale of renewable energy consumption is small. Zwaan and Rabl (2004) [36], Kobos et al. (2006) [37], Klitkou et al. (2015) [38] indicated that if energy consumption reaches a certain scale, then it can reduce the cost of energy use. That is, if renewable energy consumption fails to reach a certain scale, then the cost of developing and using renewable energy tend to be high. Thus, the low degree of energy consumption's structure transformation generates great economic costs. At this point, the energy consumption's structure transformation has reduced pollution emissions, but it is not conducive to green economic development.

The increased intensity of renewable energy consumption indicates that when the energy consumption's structure transformation degree is greater than 0.67 and less than 10.87, the renewable energy consumption has reached a certain scale. Thus, the cost of renewable energy development and use is reduced. At this point, the transformation of the energy consumption's structure has reduced the burden on the economy, which can promote green economic development.

The continuous transformation of the energy consumption's structure indicates that when its degree exceeds 10.87, the proportion of renewable energy consumption increases while the proportion of fossil energy consumption decreases. Since fossil energy has been widely used earlier. Therefore, compared with renewable energy, fossil energy better complements the needs of the production process under the existing technical conditions. Therefore, if the proportion of fossil energy consumption is reduced to a certain extent under the existing technical conditions, then production efficiency and resource utilization rates will be reduced. At this point, the transformation of energy consumption's structure is conducive to green economic development. 
In summary, under the current technical conditions, the energy consumption's structure transformation can only promote green economic development when it is within the range of $0.67-10.87$.

(2) Model 2 shows that when the TC level is lower than 0.75, the energy consumption's structure transformation exhibits a significant negative impact on green economic development, while the marginal coefficient is -0.109 . Notably, the TC level that is higher than 0.75 but lower than 1.23 weakens the negative impact of the energy consumption's structure transformation on green economic development, and the marginal coefficient is -0.008 . However, when the TC level is higher than 1.23 , the energy consumption's structure transformation has a significant positive impact on green economic development, while the marginal coefficient is 0.028 .

The results of Model 2 prove that technological innovation can stimulate the positive effect of energy consumption's structure transformation on green economic development. The development and use of renewable energy requires new and high-tech support [39]. Thus, when the technological innovation capability is insufficient, renewable energy fails to adapt to the existing production technology. At this point, although the energy consumption's structure transformation reduces pollution emissions, it also reduces production efficiency and is not conducive to green economic development. The increase of technological innovation capability has supported renewable energy by improving its cost-effective use. Thus, the transformation of energy consumption's structure exhibits a positive impact on green economic development.

In summary, new and high-tech support is the key to improving the efficiency of renewable energy use. Enhancing technological innovation capabilities can help mediate the relationship between energy consumption's structure transformation and green economic development.

(3) Model 3 shows that when the EC level is lower than 1.03, the regression coefficient of energy consumption's structure transformation for green economic development fails the significant test. Therefore, technological improvement will not affect the relationship between energy consumption's structure transformation and green economic development. By contrast, when the EC level is higher than 1.03, the energy consumption's structure transformation reveals a significant negative impact on green economic development, while the marginal coefficient is -0.142 .

This finding occurs because the existing production technology is more suitable for fossil energy than for renewable energy. Although the improvement of the existing technology can effectively improve the efficient use of fossil energy, it will not affect renewable energy. Therefore, appropriate technological improvements will not affect the relationship between the energy consumption's structure transformation and green economic development. However, excessive technological improvements consume a substantial amount of technical funds, personnel, and equipment. Thus, great economic costs are required, and a crowding out effect on technological innovation is present. Technological improvements cannot mediate the relationship between energy consumption's structure transformation and green economic development.

In summary, appropriate technological improvements fail to mediate the relationship between energy consumption's structural transformation and green economic development. Furthermore, excessive technological improvement may consequently yield negative impact in the relationship between energy consumption's structure transformation and green economic development.

(4) This study also investigates whether the degree of fossil energy dependence affects the relationship between energy consumption's structure transformation and green economic development. Model 4 reveals that when the FED level is lower than 0.13 , the energy consumption's structure transformation exhibits a significant positive impact on green economic development, while the marginal coefficient is 0.054. By contrast, when the FED level is higher than 0.13 , the energy consumption's structure transformation has a significant negative impact on green economic development, and the marginal coefficient is -0.029 .

The dependence of GDP on fossil energy is related to the relationship between energy consumption's structure transformation and green economic development based on path-dependence theory in energy consumption. Path-dependence theory posits that when the country or region's energy consumption is "locked" to fossil energy, its GDP exhibits high 
dependence on fossil energy consumption. Thus, fossil energy consumption promotes economic growth, which is similar to "inertia." In countries or regions where the degree of fossil energy dependence is high, the energy consumption's structure transformation fails to induce economic growth. Therefore, although pollution emissions are reduced, green economic development lacks improvement.

In summary, the relationship between energy consumption's structure transformation and green economic development can be mediated by reducing the GDP's dependence on fossil fuels.

We compare the fixed effect model and threshold regression models to determine whether the empirical results are robust. In all models, the regression coefficients of the control variables did not change significantly. Therefore, we believe that the threshold regression models have good robustness.

\section{Conclusions and Recommendations}

This study measures the green economic development level among the $27 \mathrm{EU}$ member countries through the SBM-GML approach. In addition, this study identifies the technological advancement approaches that can mediate the relationship between energy consumption's structure transformation and green economic development. Thus, the following conclusions are obtained, and corresponding policy recommendations are proposed.

(1) Under the existing technical conditions, the degree of energy consumption's structure transformation can only promote green economic development in the interval of $0.67-10.87$. That is, the transformation of energy consumption's structure is subject to the existing technical conditions. When the proportion of renewable energy consumption is less than $0.67 \%$, the transformation of energy consumption's structure hinders green economic development because small-scale renewable energy development and use cost a substantial amount. Renewable energy reduces pollution emissions, but it is not conducive to productivity and economic growth. Similarly, when the proportion of renewable energy consumption exceeds $10.87 \%$, the transformation of energy consumption's structure fails to induce green economic development. This finding is supported by the fact that renewable energy consumption exhibits a crowding effect on fossil energy consumption, and existing production technologies are more suitable for fossil energy than for renewable energy. Notably, the transformation of energy consumption's structure reduces production efficiency and hinders green economic development. Therefore, existing technical conditions should be improved. Moreover, the relationship between energy consumption's structure transformation and green economic development can be mediated by technological progress.

(2) Improving technological innovation capability is a key to mediate the relationship between energy consumption's structure and green economic development. Conversely, enhancing the level of technological improvement fails to mediate the relationship between energy consumption's structure transformation and green economic development. Therefore, to positively affect green economic development, we should focus on improving the ability of technological innovation instead of technological improvements when transforming energy consumption's structure. Compared with the existing technology, the development and use of renewable energy requires new and high-tech support. Furthermore, new and high-tech support improves the cost-effective use of renewable energy. Thus, technological innovation capabilities can help the energy consumption's structure transformation to promote green economic development. By contrast, improvements on existing technologies may increase the efficiency of fossil energy use and reduce pollution emissions. However, they fail to mediate the relationship between energy consumption's structure transformation and green economic development. Furthermore, the excessive use of technical resources to improve existing technologies will crowd out technological innovation. Therefore, the transformation of energy consumption's structure occurs, which is not conducive to green economic development. 
(3) The relationship between energy consumption's structure transformation and green economic development can also be mediated by reducing the GDP's dependence on fossil fuels. In countries where the energy consumption's structure is "locked" to fossil energy, the production technology is more suitably used for fossil energy than for renewable energy. Although the energy consumption's structure transformation reduces pollution emissions, it is not conducive to promoting production efficiency and economic growth. Thus, the transformation of energy consumption's structure cannot promote green economic development. To mediate the transformation of energy consumption's structure that promotes green economic development, we must prioritize and adjust the industrial structure and rationally allocate resources to reduce the GDP's on fossil energy prior to increasing the intensity of renewable energy consumption.

\author{
Abbreviations: \\ GDP: Gross Domestic Product \\ EU: European Union \\ GML: Global-Malmquist-Luenberger \\ SBM: Slacks-Based Measure \\ Green: green economic development \\ EST: Energy consumption's structure transformation \\ TC: Technological innovation \\ EC: Technical efficiency \\ FED: Fossil energy dependence \\ DEN: The population density (DEN) \\ GOV: Government intervention (GOV) \\ UNE: Unemployment rate (UNE)
}

\title{
Declarations:
}

Ethics approval and consent to participate: Not applicable.

Consent for publication: All authors agreed to publish the paper.

Availability of data and materials: The datasets obtained and analyzed in the current study are available from the corresponding author on reasonable request.

Competing interests: The authors declare that they have no competing interests.

Funding: This research was funded by the "Double-First Class" Think Tank Program of China University of Mining and Technology (Grant No. 2018WHCC01).

Author Contributions: conceptualization, F.X. and Y.L.; methodology, F.X. and Y.L; software, F.X. and Y.L; validation, F.X., Y.L. and F.G.; formal analysis, F.X.; investigation, Y.L.; resources, F.X., Y.L. and N.W.; data curation, F.X., Y.L. and N.W; writing-original draft preparation, F.X., Y.L. and F.G; writing-review and editing, F.X., Y.L., F.G. and N.W.; visualization, F.X. and Y.L.; supervision, Y.L.; project administration, F.X. and Y.L.; funding acquisition, Y.L.

Acknowledgments: The authors are grateful for the financial support provided by the "Double-First Class" Think Tank Program of China University of Mining and Technology (No.2018WHCC01).

Author information: Affiliations

School of Management, China University of Mining \& Technology, Xuzhou 221116, China

Fangming Xie, Yali Liu, and Fangyuan Guan

Jiangsu normal university kewen college, Xuzhou 221116, China

Ning Wang

\section{References}


1. Okafor-Yarwood I., 2019. Illegal, unreported and unregulated fishing, and the complexities of the sustainable development goals (SDGs) for countries in the Gulf of Guinea. J. Marine Policy. 99, 414-422. https://doi.org/10.1016/j.marpol.2017.09.016

2. BP Statistical Review of World https://www.bp.com/en/global/corporate/energy-economics/statistical-review-of-world-energy.html. (accessed 20 December 2019).

3. Knopf B, Nahmmacher P, Schmid E., 2015. The European renewable energy target for 2030-An impact assessment of the electricity sector. J. Energy policy. 85, 50-60. https://doi.org/10.1016/j.enpol.2015.05.010

4. Van Der Ploeg R, Withagen C., 2013. Green growth, green paradox and the global economic crisis. J. Environmental innovation and societal transitions. 6, 116-119. https://doi.org/10.1016/j.eist.2012.11.003

5. Tugcu C T, Ozturk I, Aslan A., 2012. Renewable and non-renewable energy consumption and economic growth relationship revisited: evidence from G7 countries. J. Energy economics. 34(6), 1942-1950. https://doi.org/10.1016/j.eneco.2012.08.021

6. Lin B, Moubarak M., 2014. Renewable energy consumption-economic growth nexus for China. J. Renewable and Sustainable Energy Reviews. 40, 111-117. https://doi.org/10.1016/j.rser.2014.07.128

7. Apergis N, Payne J E., 2010. Renewable energy consumption and growth in Eurasia. J. Energy Economics. 32(6), 1392-1397. https://doi.org/10.1016/j.eneco.2010.06.001

8. Sebri M, Ben-Salha O., 2014. On the causal dynamics between economic growth, renewable energy consumption, CO2 emissions and trade openness: Fresh evidence from BRICS countries. J. Renewable and Sustainable Energy Reviews. 39, 14-23. https://doi.org/10.1016/j.rser.2014.07.033

9. Marinas, M.C.; Dinu, M.; Socol, A.G.; Socol, C., 2018. Renewable energy consumption and economic growth. Causality relationship in Central and Eastern European countries. J. PLoS ONE. 13. e0202951. https://doi.org/10.1371/journal.pone.0202951

10. Shafiei S, Salim R A., 2014. Non-renewable and renewable energy consumption and CO2 emissions in OECD countries: A comparative analysis. J. Energy Policy. 66, 547-556. https://doi.org/10.1016/j.enpol.2013.10.064

11. Bhattacharya M, Paramati S R, Ozturk I, et al., 2016. The effect of renewable energy consumption on economic growth: Evidence from top 38 countries. J. Applied Energy. 162, 733-741. https://doi.org/10.1016/j.apenergy.2015.10.104

12. Paramati S R, Apergis N, Ummalla M., 2018. Dynamics of renewable energy consumption and economic activities across the agriculture, industry, and service sectors: evidence in the perspective of sustainable development. J. Environmental Science and Pollution Research. 25(2), 1375-1387.

13. Rahman M M, Velayutham E., 2020. Renewable and non-renewable energy consumption-economic growth nexus: New evidence from South Asia. J. Renewable Energy. 147, 399-408. https://doi.org/10.1016/j.renene.2019.09.007

14. Inglesi-Lotz R., 2016. The impact of renewable energy consumption to economic growth: A panel data application. J. Energy Economic. 53, 58-63. https://doi.org/10.1016/j.eneco.2015.01.003

15. Alper A, Oguz O., 2016. The role of renewable energy consumption in economic growth: Evidence from asymmetric causality. J. Renewable and Sustainable Energy Reviews. 60, 953-959. https://doi.org/10.1016/j.rser.2016.01.123

16. Eren B M, Taspinar N, Gokmenoglu K K., 2019. The impact of financial development and economic growth on renewable energy consumption: Empirical analysis of India. J. Science of the Total Environment. 663, 189-197. https://doi.org/10.1016/j.scitotenv.2019.01.323

17. Ocal O, Aslan A., 2013. Renewable energy consumption-economic growth nexus in Turkey. J. Renewable and sustainable energy reviews. 28, 494-499. https://doi.org/10.1016/j.rser.2013.08.036

18. Destek M A., 2016. Renewable energy consumption and economic growth in newly industrialized countries: Evidence from asymmetric causality test. J. Renewable Energy. 95, 478-484. https://doi.org/10.1016/j.renene.2016.04.049

19. Wang Z, Zhang B, Wang B., 2018. Renewable energy consumption, economic growth and human development index in Pakistan: evidence form simultaneous equation model. J. Journal of cleaner production. 184, 1081-1090. https://doi.org/10.1016/j.jclepro.2018.02.260

20. Khoshnevis Yazdi S, Shakouri B. Renewable energy, nonrenewable energy consumption, and economic growth[J]. Energy Sources, Part B: Economics, Planning, and Policy, 2017, 12(12): 1038-1045. (https://doi.org/10.1080/15567249.2017.1316795) 
21. Sasana H, Ghozali I., 2017. The impact of fossil and renewable energy consumption on the economic growth in Brazil, Russia, India, China and South Africa. J. International Journal of Energy Economics and Policy. 7(3), 194-200.

22. Magazzino C., 2017. Renewable energy consumption-economic growth nexus in Italy. J. International Journal of Energy Economics and Policy. 7(6), 119-127.

23. Ozcan B, Ozturk I., 2019. Renewable energy consumption-economic growth nexus in emerging countries: A bootstrap panel causality test. J. Renewable and Sustainable Energy Reviews. 104, 30-37. https://doi.org/10.1016/j.rser.2019.01.020

24. Destek M A, Aslan A., 2017. Renewable and non-renewable energy consumption and economic growth in emerging economies: Evidence from bootstrap panel causality. J. Renewable Energy. 111, 757-763. https://doi.org/10.1016/j.renene.2017.05.008

25. Narayan S, Doytch N., 2017. An investigation of renewable and non-renewable energy consumption and economic growth nexus using industrial and residential energy consumption. J. Energy Economics. 68, 160-176. https://doi.org/10.1016/j.eneco.2017.09.005

26. Xie F, Liu C, Chen H, et al., 2018. Threshold Effects of New Energy Consumption Transformation on Economic Growth. J. Sustainability. 10(11), 4124. https://doi.org/10.3390/su10114124

27. Destek M A, Sinha A., 2020. Renewable, non-renewable energy consumption, economic growth, trade openness and ecological footprint: Evidence from organisation for economic Co-operation and development countries. J. Journal of Cleaner Production. 242, 118537. https://doi.org/10.1016/j.jclepro.2019.118537

28. Luenberger D G. Microeconomic theory., 1995. Mcgraw-Hill College.

29. Chung Y H, Färe R, Grosskopf S., 1997. Productivity and undesirable outputs: a directional distance function approach. J. journal of Environmental Management 51(3), 229-240. https://doi.org/10.1006/jema.1997.0146

30. Yörük B K, Zaim O., 2005. Productivity growth in OECD countries: A comparison with Malmquist indices. J. Journal of Comparative Economics. 33(2), 401-420. https://doi.org/10.1016/j.jce.2005.03.011

31. Kumar S., 2006. Environmentally sensitive productivity growth: a global analysis using Malmquist-Luenberger index. J. Ecological Economics. 56(2), 280-293. https://doi.org/10.1016/j.ecolecon.2005.02.004

32. Feng G, Serletis A., 2014. Undesirable outputs and a primal Divisia productivity index based on the directional output distance function. J. Journal of Econometrics. 183(1), 135-146. https://doi.org/10.1016/j.jeconom.2014.06.014

33. Oh D., 2010. A global Malmquist-Luenberger productivity index. J. Journal of productivity analysis. 34(3), 183-197.

34. Hansen B E., 1999. Threshold effects in non-dynamic panels: Estimation, testing, and inference. J. Journal of econometrics. 93(2), 345-368. https://doi.org/10.1016/S0304-4076(99)00025-1

35. Arthur W B., 1994. Increasing returns and path dependence in the economy. University of michigan Press.

36. Van der Zwaan B, Rabl A., 2004. The learning potential of photovoltaics: implications for energy policy. J. Energy Policy. 32(13), 1545-1554. https://doi.org/10.1016/S0301-4215(03)00126-5

37. Kobos P H, Erickson J D, Drennen T E., 2006. Technological learning and renewable energy costs: implications for US renewable energy policy. J. Energy policy. 34(13), 1645-1658. https://doi.org/10.1016/j.enpol.2004.12.008

38. Klitkou A, Bolwig S, Hansen T, et al., 2015. The role of lock-in mechanisms in transition processes: The case of energy for road transport. J. Environmental Innovation and Societal Transitions. 16, 22-37. https://doi.org/10.1016/j.eist.2015.07.005

39. Sawhney A, Kahn M E., 2012. Understanding cross-national trends in high-tech renewable power equipment exports to the United States. J. Energy Policy. 46, 308-318. https://doi.org/10.1016/j.enpol.2012.03.066 
Figures

\section{1}

0.09

0.08

0.07

0.06

0.05

0.04

0.03

0.02

0.01

0

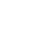

